\title{
The Counselors for Social Justice (CSJ) Code of Ethics
}

Note: Developed by the 2009 - 2010 Counselors for Social Justice (CSJ) Ethics Committee in collaboration with CSJ membership and formally endorsed by the CSJ Board of Directors, September 2010

Committee Chairperson and Members include: Farah A. Ibrahim, Chair, Counseling Psychology and Counselor Education, University of Colorado Denver; Julie A. Dinsmore, Department of Counseling and School Psychology, University of Nebraska at Kearney; Diane Estrada, Counseling Psychology and Counselor Education, University of Colorado Denver; Michael D’Andrea, Ad Hoc Committee Member, 2009 - 2010 CSJ President

\begin{abstract}
Part 1 of this article features the Counselors for Social Justice (CSJ) Code of Ethics formally endorsed in 2010. The ethical standards for practice, advocacy, assessment and diagnosis, supervision, research, and professional relationships, including consultation are outlined. In Part 2, following the presentation of the Code of Ethics, the mission and goals of CSJ as well as the process, and the development of the CSJ Code of Ethics are described.
\end{abstract}

Keywords: social justice, ethics, standards

\section{Part 1: Counselors for Social Justice Code of Ethics}

The Counselors for Social Justice (CSJ) Code of Ethics was developed by the 2009 - 2010 Counselors for Social Justice (CSJ) Ethics Committee in collaboration with CSJ membership and formally endorsed by the CSJ Board of Directors in September, 2010. The CSJ Code of Ethics identifies a set of guiding ethical principles that are particularly relevant for the work professional counselors do from a social justice perspective. By specifying action steps in the 
content of this code, the following information helps to clarify how social justice-oriented counselors can transition ethical intent to ethical practice. A full discussion of the rationale for the CSJ Code of Ethics, the historical background of CSJ as an organization, and the development process for the CSJ Ethics Code can be found following the body of the Ethics Code.

\section{The CSJ Code of Ethics}

CSJ recognizes the commitment of its members to the ACA Code of Ethics (2005). Consequently, this document is not meant to supplant the ACA Code but rather to clarify for the membership of CSJ the application and expansion of the ACA Code of Ethics from a social justice orientation. Consequently, the CSJ Code of Ethics is designed to serve five main purposes:

- The CSJ Code of Ethics clarifies the nature of the ethical responsibilities CSJ members strive to follow in their professional practices.

- The CSJ Code helps to operationalize the mission of the CSJ.

- The Code defines best practices and ethical behavior for CSJ members.

- The Code serves as a resource for CSJ members to refer when determining a course of action that best promotes the values of the organization.

- The Code is designed to assist social justice-oriented counselors in ethical decisionmaking.

The CSJ Code of Ethics delineates six guiding ethical principles and applies those principles to five dimensions of counseling and social justice advocacy practice: counseling practice/advocacy; assessment and diagnosis; supervision, training and teaching; research; and consultation and professional relationships.

\section{Guiding Principles for the Ethical Code}

CSJ members are dedicated recognizing and supporting diversity when implementing culturallysensitive helping strategies that are aimed at enhancing the development, dignity, potential, empowerment, and uniqueness of all individuals within their social-cultural environments. The six guiding principles that underlie the CSJ Code of Ethics are anchored in the following six core values.

Social justice. Social justice requires that CS] professionals recognize historical, social, and political inequities in the treatment of people from non-dominant groups and work to remove such inequities at the individual, institutional and societal levels. Such efforts require social justice minded counselors to be ever vigilant of the various injustices and different types of oppression that contribute to people's mental health problems as these professionals work to create an equitable and fair social system. 
Social action. A primary reason for the establishment of CSJ was to confront issues of social injustice. This professional organization is thus grounded in the belief that it is not enough for counselors to simply become aware and knowledgeable of the ways that social injustices undermine people's mental health and well-being. They are also responsible for using this awareness and knowledge to implement actions that are intentionally designed to ameliorate various injustices that adversely impact diverse client populations.

Although many mental health organizations recognize social justice as a value, few mental health organizations explicitly state that one of their main goals is to confront social injustice as a key professional value. CSJ professionals are ethically committed to identify social injustice; educate professionals in schools, colleges, institutions, and communities about the adverse impact of such injustice; and take action to eradicate injustices through advocacy. Furthermore, the CS] Code of Ethics is based in the realization that activism is a part of the social justice-oriented counselor's personal and professional identity development (Roysircar, 2009).

Eradication of all forms of abuse and oppression. This principle affirms the importance of confronting social ills that lead to abuse, neglect, exclusion, and oppression of individuals and marginalized groups in schools, organizations, and communities. It involves increasing awareness and knowledge of social justice issues through advocacy and social actions that address mental and physical health issues and crises that people experience as a result of oppression. When operating from this ethical principle, mental health professionals demonstrate their willingness to accept the responsibility of working to eradicate all forms of injustice and oppression that clients in diverse and marginalized populations encounter in their lives.

Dignity and worth of all persons. This principle requires CSJ professionals to be aware of and understand their own of the worldview (beliefs, values and assumptions) and cultural/racial identity as well as the multiple identities of their clients/students that are impacted by various social-cultural-contextual factors. It also underscores one's ethical commitment to convey respect for the dignity and worth of one's clients/students in culturally sensitive and responsive ways. This ethical commitment is specifically manifested in the respectful manner that social justice-oriented counselors collaborate with their clients/students when developing goals and strategies for counseling, education, and supervision in culturally relevant and responsive ways.

The principle of dignity and worth of all persons includes ethical responsibilities associated with the selection and use of evaluation and assessment strategies. In short, these responsibilities require social justice-oriented counselors to be knowledgeable of the evaluation and assessment strategies that have been developed for use with the specific cultural groups that their clients/students identify. It is particularly important for social justice-oriented counselors to be knowledgeable of the limits and cultural biases associated with different testing protocols and methods that are currently used in the profession.

This ethical responsibility also requires counselors to assess their clients' cultural identity and make diagnoses that are congruent with the worldview and values of the client's culture group rather than making more general diagnoses based on culturally-biased interpretations of presenting symptoms. Furthermore, the ethical principle related to the dignity and worth of all 
persons includes the use of evidence-based therapeutic approaches that are valid for the client and his or her cultural group as well as maintaining confidential counseling records according to state and federal mandates.

Embracing diversity. This ethical principle addresses the importance of accurately identifying the strengths and challenges of culturally-diverse clients/students as well as the communities in which they are situated. It requires counseling professionals and social justice advocates to commit themselves to a process of life-long learning that enables them to overcome their personal/cultural biases. In situations where social-justice oriented counselors believe their personal/cultural biases may be detrimental in the helping process, they agree to refer clients to an appropriate mental health provider.

Integrity and competence. All CSJ professionals must act with integrity and work to achieve competence in all their roles as counselors, educators, advocates, and community members. This implies not going beyond their training/education and commits them to continue education and professional development activities to learn ways to more effectively confront issues of oppression and social injustice at the micro and the macro level. These professionals are active in the counseling profession, their local communities, and in addressing social injustices that are global in nature.

The following sections of the CSJ Code of Ethics outline the parameters of ethical practice and behavior in five areas: Counseling Practice/Advocacy, Assessment and Diagnosis, Supervision, Training and Teaching, Research, and Professional Relationships and Consultation.

\section{Code A: Counseling Practice/Advocacy}

Among the ethical responsibilities of CSJ professionals who provide counseling services to culturally diverse clients is to respect the dignity and promote the welfare of the persons they serve (ACA Code of Ethics, 2005, A.1.a). In counseling practice, this includes being aware of clients' worldviews, cultural/racial identity, and the impact of the social-cultural contexts in which they live and work. When working in counseling situations, CS] professionals recognize the power and privilege hierarchies that exist in their clients' environments as a result of historical and current social-political conditions.

CSJ professionals recognize that not all problems clients/students experience are the result of intra-psychic factors, but many often emerge from and are sustained by factors in the environment in which they live. Laws, institutional policies and procedures, and social environments that are unjust and oppressive can lead to situational and chronic developmental, social and emotional problems that clients/students experience. CS] professionals assume the ethical responsibility to address these factors by providing counseling and advocacy services either with or on behalf of the clients/students with whom they work.

A.1 Practice. CSJ counseling professionals "do not condone or engage in discrimination based on age, culture, disability, ethnicity, race, religion/spirituality, gender, gender identity, sexual orientation, marital status/partnership, language preference, socioeconomic status, or any basis proscribed by law . . . in a manner that has a negative impact on [clients/students]" (ACA Code of Ethics, 2005, C.5, p. 5). CSJ counseling professionals understand that, who a person is (e.g. one's cultural worldview, identity development level, gender, sexual orientation, 
sociopolitical status and socioeconomic experience), always informs how one uses what one knows.

These counseling practitioners recognize that the socializing influence of professional organizations can predispose them to a particular view of what is considered to be normal, desirable and healthy. Consequently, to avoid harm to their clients, social justice-oriented practitioners must take steps to become aware of their own values, attitudes, beliefs, and assumptions and avoid imposing them (ACA Code of Ethics, 2005, A.4.b) in ethnocentric, unintentionally racist, and other potentially damaging ways when working with culturallydifferent clients, students and/or research participants.

CSJ counseling professionals have the ethical responsibility to become aware of personal values, moral beliefs, stereotypes, prejudices, and racist attitudes or behaviors that would prevent them from providing competent and ethical services to clients/students. They are responsible for remediating these barriers, and if unable to do so, to avoid entering into or continuing counseling relationships that could result in client/student harm.

CSJ professional do not abandon clients/students but refer them to professionals who can provide ethical, supportive, and culturally responsive services (ACA Code of Ethics, 2005, A.11.a). In addition, they are responsible to assist colleagues or supervisors to recognize their own professional impairment in this regard and provide consultation and assistance when warranted and interventions when appropriate to prevent harm to clients/students (ACA Code of Ethics, 2005, C.2.g).

CSJ counseling professionals recognize that clients/students have the freedom to choose whether to enter into or remain in a counseling or mentoring relationship. They further recognize they have an obligation to assure that clients/students understand the nature and purpose of the counseling or mentoring process, and the rights and responsibilities of both the client/student and the counselor (ACA Code of Ethics, 2005, A.2). They communicate information in developmentally and culturally appropriate ways, using clear language when discussing informed consent.

When clients/students have difficulty understanding the language used by the counselor, it is the counselor's responsibility to provide qualified interpretation and/or translation services to assure client/student understanding (ACA Code of Ethics, 2005, A.2.c). With client/student consent, CSJ professionals collaborate with others in the support system of the client/student (ACA Code of Ethics, 2005, A.1.d), including those providing indigenous helping practices.

A.2. Advocacy. CSJ counseling professionals, when appropriate, advocate at individual, group, institutional, and societal levels to address barriers and obstacles that inhibit access and/or clients'/students' development (ACA Code of Ethics, 2005, A.6.a). They explain to clients/students their social justice orientation and the boundaries of advocacy in which they can engage to support client/student development and resolution of the client's/student's concerns.

CSJ professionals obtain client/student consent prior to engaging in advocacy efforts on behalf of clients/students (ACA Code of Ethics, 2005, A.6.b). CSJ professionals work collaboratively with clients/students to develop goals and strategies for counseling (ACA Code of Ethics, 2005, 
A.1.c) and advocacy efforts that are culturally sensitive and relevant. These professionals affirm the historical, social, and political inequities related to the client's/student's experience and facilitate increased awareness of the relationship of these inequities to client/student issues.

It is the ethical responsibility of CSJ professionals to support client/student self-advocacy in an effort to address these inequities. It is also important that CSJ professionals be prepared to take social action themselves to help remove these inequities and create a more equitable and fair institutional, community or social system.

A.2.a. Direct individual client/student empowerment interventions. In the context of individual counseling, when CSJ professionals and their clients/students recognize that either internalized oppression or external barriers negatively impact client/student well-being, CS] professionals have the ethical responsibility to support client/student empowerment. According to Lewis, Arnold, House \& Toporek (2002), this may be accomplished by seeking to:

(a) identify strengths and resources of clients and students;

(b) identify the social, political, economic, and cultural factors that affect the client/student;

(c) recognize the signs indicating that an individual's behaviors and concerns reflect responses to systemic or internalized oppression;

(d) . . . help the individual identify the external barriers that affect his or her development

(e) train students and clients in self-advocacy skills;

(f) help students and clients develop self-advocacy action plans;

(g) assist students and clients in carrying out action plans. (para. 1)

A.2.b. Individual client/student advocacy interventions. When CS] professionals "become aware of external factors that act as barriers to an individual's development," (Lewis et al., 2002, para. 2) particularly "when individuals or vulnerable groups lack access to needed services" (Lewis et al., 2002, para. 2), they consider the benefits that can be derived from implementing social justice advocacy services and discuss such interventions with their clients/students. These interventions (Lewis et al., 2002) include the ability to:

(a) negotiate relevant services and education systems on behalf of clients and students,

(b) help clients and students gain access to needed resources,

(c) identify barriers to the well-being of individuals and vulnerable groups,

(d) develop an initial plan of action for confronting these barriers,

(e) identify potential allies for confronting the barriers

(f) carrying out the plan of action. (para. 2)

A.2.c. Community advocacy interventions. When CSJ professionals become aware of environmental factors that impinge upon the development of groups of clients/students, they assume the role of ally to promote collaboration toward the development of advocacy plans to address the injustices experienced by client/student groups. These professionals collaborate with organizations or client/student groups by displaying the ability (Lewis, et al., 2002) to: 
(a) alert community or school groups with common concerns related to the issue,

(b) develop alliances with groups working for change,

(c) use effective listening skills to gain an understanding of the group's goals,

(d) identify the strengths and resources that the group members bring to the process of systemic change,

(e) communicate recognition of and respect for these strengths and resources,

(e) identify and offer the skills that the counselor can bring to the collaboration,

(f) assess the effect of counselor's interaction with the community. (para. 3)

A.2.d. Systems advocacy interventions. When CSJ professionals identify systemic factors that act as barriers to client/student development, they exert systems-change leadership at the school or community level by displaying the ability (Lewis, et al., 2002) to:

(a) identify environmental factors impinging on students' or clients' development,

(b) provide and interpret data to show the urgency for change,

(c) in collaboration with other stakeholders, develop a vision to guide change,

(d) analyze the sources of political power and social influence within the system,

(e) develop a step-by-step plan for implementing the change process and . . . dealing with probable responses to change,

(f) recognize and deal with resistance,

(g) assess the effect of counselor's advocacy efforts on the system and its constituents. (para. 4)

A.2.e. Public information advocacy interventions. CSJ professionals inform the public about the impact of oppression on healthy development as well as factors protective of such development by displaying the ability (Lewis, et al., 2002) to:

(a) prepare [and disseminate] written and multi-media materials that provide clear explanations of the role of specific environmental factors in human development,

(b) communicate information in ways that are ethical and appropriate for the target population,

(c) identify and collaborate with other professionals who are involved in disseminating public information,

(d) assess the influence of public information efforts undertaken by the counselor. (para. 5)

A.2.f. Social/political advocacy interventions. CS] professionals act as change agents in the systems that negatively affect their clients/students by displaying the ability to:

(a) distinguish those problems that can best be resolved through social/political action (Lewis, et al., 2002, para. 6),

(b) maintain open dialogue with communities and clients to ensure that the social/political advocacy is consistent with the initial goals (Lewis, et al., 2002, para. 6),

(c) seek out avenues and existing alliances for change,

(d) join with allies to prepare data to support change and lobby legislators and policy decision-makers

\section{Code B: Assessment and Diagnosis}


CSJ professionals take the client's/student's personal, social, and cultural context into account when conducting assessments and developing a diagnosis (Ibrahim \& Arredondo, 1986). The instruments used must be relevant for the specific client/student and the counseling process. The assessment and diagnostic activities must promote the wellbeing and empowerment of the client/student within his or her context.

Diagnosis must be relevant to the client's/student's cultural-social context, taking into account the sociopolitical history and current conditions within which the client/student lives and works (Lonner \& Ibrahim, 2008). CSJ professionals develop and use appropriate educational, psychological, and career assessment instruments. They only use culturally-valid and reliable instruments and assessment strategies that they have had training in and develop new culturally-valid and reliable instruments if they are trained in test development.

B.1.a. Assessment and diagnosis. CSJ professionals use assessment measures that are useful in developing accurate diagnoses and treatment plans that are designed to empower clients/students by assisting them in acquiring new knowledge and skills that enable clients/students to effectively address environmental challenges in general and social injustices in particular. These measures include methods to assess:

(a) clients'/students' cultural/racial and gender identity development, level of acculturation, and the impact of privilege-oppression, and

(b) their educational, psychological, and career strengths and needs to facilitate the counseling process using a culturally responsive and ethical approach to helping (Lonner \& Ibrahim, 2008). CSJ professionals recognize that the statements in this section apply to both quantitative and qualitative measures.

The ACA Code takes a strong position on the cultural ramifications of labeling clients with an inappropriate diagnosis or as having pathology (2005, E.5.c). Eriksen and Kress (2005) challenge traditional notions of what abnormal behavior is and who decides the criteria that determine whether or not a client has a mental disorder. They note that inappropriately diagnosing a client can have a negative impact on client wellbeing. Such inappropriate diagnoses can lead many women and people from marginalized communities to feel disempowered and/or to experience harmful thoughts and feelings about themselves and others. The 2005 ACA Code of Ethics addresses this issue in Standard E.5. c which directs counselors to "recognize historical and social prejudices in the misdiagnosis and pathologizing of certain individuals and groups and the role of mental health professionals in perpetuating these prejudices through diagnosis and treatment" (p. 12).

B.1.b. Clients'/students' welfare and empowerment. CS] professionals keep the welfare and empowerment of clients/student as a primary goal when conducting assessments. These professionals recognize that their role is to empower clients/students and increase their resilience through counseling, advocacy, teaching, consultation, and forensic evaluations.

CSJ professionals are cautious in using assessments, especially tests that are not designed for the specific cultural group the client/student represents. These professionals also make every effort to avoid the misuse of assessment information and ensure the privacy and confidentiality of test results. If assessments and diagnoses might lead to negative client/student consequences, CSJ professionals may choose to not conduct such an assessment and refrain 
from providing a diagnostic label that may potential lead to harmful consequences for the client/student.

CSJ professionals respect the client's/student's right to know the results of assessments made of them, the interpretations generated from such assessments, and the basis for counselors' conclusions and recommendations. When assessments are done in a socially just manner (i.e., by addressing the above stated ethical issues), the results and conclusions are drawn collaboratively with clients/students by involving them in the assessment process to arrive at more accurate conclusions about the results and diagnoses.

B.2. Recognition of historical, social, and cultural oppressions. CS] professionals recognize the impact of socio-historical and cultural oppressions and the effect they have had on historically oppressed groups. In using assessment data and making diagnoses based on such data, CSJ professionals are sensitive to clients'/students' context and the current oppressions and exclusions they face in their lives. They inform clients/students that, upon receiving their permission, counselors can advocate with their clients/students' and are able to use assessment strategies to enhance clients'/students' ability to advocate for themselves in familial, work, and other social-cultural environments.

For example, in conducting forensic evaluations, CSJ professionals can develop a case study based that is based on their clients'/students' experiences and their response to the oppressions and injustices they experience in oppressive environments. In this context, cultural assessments listed above in B.1.a may be most helpful in advocating for the client/student.

CSJ professionals take action to prevent others from misusing the information these evaluation techniques provide, and advocate for assessments and diagnoses to be conducted in socially just and culturally sensitive ways. These professionals advocate for this issues in their professional associations, conduct research on acceptable use of psychological tests, and educate other persons in the counseling profession and the communities where they work about the misuse of assessment data and misdiagnoses of historically oppressed groups (ACA, 2005, E.5.c).

B.3.a. Integrity and competence. CSJ professionals are mandated to maintain their integrity and competence on issues of assessment and diagnosis, as they conduct assessments, teach, or provide consultations about methods of assessment and diagnoses. They are encouraged to seek continuing education and peer supervision when confronted with unique situations that merit additional knowledge and training in assessment, diagnosis and client vulnerability in these domains.

\section{Code C: Supervision, Training and Teaching}

CSJ professionals, who are counselor educators, have theoretical, practice and pedagogical competence regarding a social justice orientation in counseling and the role of the counselor as client/student and community/systems advocate. These professionals endorse a multiple perspectives approach to training that assures voice to the diversity represented by their counselors-in-training. 
C.1. Counselor supervision and client/student welfare. CSJ professionals recognize that the primary obligation of counseling supervisors is to monitor the services provided by other counselors and counselors-in-training. Counseling supervisors monitor client welfare and supervisee clinical performance and professional development. These obligations are met by meeting with supervisees on a regular basis to review case notes, samples of clinical work, or live observations (ACA Code of Ethics, 2005, F.1. a). They also integrate a social justice lens by being aware of the clients and supervisees worldview, cultural/racial identity, and the socialcultural context in which clients/students live and work.

Counseling supervisors recognize the historical, social and political inequities in the treatment of people, in policies and procedures in schools, organizations, and communities. Supervisors are pro-active in teaching their supervisees to identify social justice issues in their client cases. Furthermore, supervisors model and support an active stance supervisees take when educating other persons in schools, colleges, professional institutions/organizations, and communities regarding the importance of advocating for the eradication of social injustices that adversely impact the lives of their clients and other people in the community.

Counseling supervisors inform their supervisees of the impact of inequity and social ills on clients' mental and physical health and the crises that result from the perpetuation of different types of inequity, exclusion, racism, sexism, homophobia, ageism, ableism, religious bigotry, and other oppressive behaviors in society. To eradicate all forms of abuse and oppression, counseling supervisors and practitioners must be willing to confront injustice and support advocacy for equity in human lives. In striving to achieve these goals, counseling supervisors support the dignity and worth of supervisees and their clients by continuously increasing awareness, knowledge and skills when working with supervisees and clients alike from a culturally-responsive counseling perspective.

C.2. Counselor supervision competence. Prior to offering supervision services, counselors are trained in supervision methods and techniques (ACA Code of Ethics, 2005, F. 2. a) that are inclusive of multicultural and diversity issues as well as social justice counseling and advocacy issues. Counseling supervisors, operating from a social justice perspective, engage in continuing education that increases their skills in delivering culturally responsive and socially just supervision and counseling services.

To provide competent services in the aforementioned areas, supervisors must have an understanding of how privilege and oppression have created hierarchies in society. Socially just and culturally responsive supervisors recognize their biases and work to educate themselves to overcome them. When counseling supervisors become aware of biases that they or their supervisees are unable to manage, a referral to another appropriate counseling supervisor or practitioner must be provided.

To fully embrace diversity, counseling supervisors must explore their own level of privilege and oppression. They must also recognize and acknowledge supervisees' and clients' strengths and challenges, and provide advocacy services that are intentionally designed to create an equitable society in which all can thrive and realize the human potential.

C.3. Supervisory relationships and responsibilities. Counseling supervisors operating from a social justice perspective are aware of the power differential in their relationships with 
supervisees. If they believe nonprofessional relationships may be potentially beneficial to the supervisee, they take precautions similar to those taken by counselors when working with clients. An example of such relationship is mutual membership in a professional association or community organization (ACA Code of Ethics, 2005, F.3.e). As community advocates, counseling supervisors and supervisees may find themselves members of similar organizations. Counseling supervisors engage with their supervisees in an open dialogue about their nonprofessional roles as advocates and delineate benefits, drawbacks, and anticipated consequences for the supervisee.

Counseling supervisors make their supervisees aware of professional, ethical, and legal standards (ACA Code of Ethics, 2005, F.4.C) including the CSJ ethical principles that explicitly support social justice, social action, eradication of all forms of abuse and oppression, upholding the dignity and worth of the person, embracing diversity, integrity, and competence. Counseling supervisors document and provide supervisees with ongoing performance appraisal and evaluation feedback (ACA Code of Ethics, 2005, F.5.a) that includes the supervisee's ability to enact the social justice ethical principles delineated in this code in their counseling practice.

C.4. Responsibilities of counselor educators. CSJ professionals, who are counselor educators, are responsible for developing, implementing and supervising educational programs that demonstrate commitment to multicultural/diversity competence. Similarly, these professionals validate the oppressions faced by clients/students, including institutional and systemic barriers that create mental health issues, and assume the responsibility to prepare trainees to identify and pursue the types of ethical social justice counseling and advocacy that are necessary to address injustices in their work. They are knowledgeable of the Multicultural (Sue, Arredondo, \& McDavis, 1992) and Advocacy (Lewis, et al., 2002) Competencies endorsed by the American Counseling Association, are skilled in applying that knowledge, and act as role models for advocacy action.

Counselor educators operating from a social justice perspective recognize and appreciate the diverse cultural perspectives and types of abilities students bring to the training experience and support diverse students' wellbeing and academic performance (ACA Code of Ethics, 2005, F.11.b). They provide prospective trainees with information about the social justice orientation within the training program and about the program's expectations for counselors-in-training to embrace that orientation as well as the responsibilities a social justice counseling professional addresses when providing counseling and advocacy services in the field. CSJ professionals, who are counselor educators, are committed to recruiting and retaining a diverse faculty and student body.

C.4.a. Infusing social justice counseling and Advocacy Competencies in the curriculum. CSJ professionals, who are counselor educators, make counselors-in-training aware of their counseling and advocacy responsibilities. They do this by not only assuring that multiculturalism/diversity issues are infused into all courses and workshops for the development of professional counselors, but that both theoretical and practice content related to the Advocacy Competencies (Lewis, et al., 2002) are represented throughout the counselor education curriculum.

These professionals help to develop and implement education and training programs that integrate knowledge of client/student and community/social advocacy with supervision 
practice. They also help to guarantee that field placements provide counselors-in-training with the opportunity to work with a diverse clientele in order to apply and further develop their skills in client/student and community/social advocacy as outlined in the Multicultural and Advocacy Competencies (Lewis, et al., 2002, Sue, Arredondo, \& McDavis, 1992).

C.4.b. Self-growth experiences. CSJ professionals, who are counselor educators, work collaboratively with counselors-in-training to assure that training goals maximize trainees' strengths that emerge from their diverse backgrounds and experiences. Counseling faculty operating from a social justice perspective assure that both curricular and extracurricular experiences are available to trainees that challenge them to recognize their own potential for unintentionally perpetuating oppression through stereotyping, prejudice, privilege, racism, sexism, classism, heterosexism, or other forms of oppression related to different group memberships such as age, religion, disability or immigrant status.

C.5 Responsibilities of counselors-in-training. CSJ counselors-in-training have a responsibility to understand the Multicultural and Advocacy Competencies (Lewis, et al., 2002, Sue, Arredondo, \& McDavis, 1992) endorsed by the American Counseling Association and to recognize that they have the same obligation to clients/students as those required of ACA and CSJ professionals (ACA Code of Ethics, 2005, F.8.a). These counselors-in-training understand and acknowledge the privileges mental health professionals enjoy as a result of their education and training. CSJ counselors-in-training refrain from offering or providing counseling services when stereotypes or prejudices they hold towards certain client groups are likely to harm a client/student or others. They are alert to signs of such impairment, notify counseling faculty or supervisors when they are unable to effectively provide services, and seek assistance in arranging an appropriate referral. Counselor-in-training who aspire to operate from a social justice perspective seek appropriate professional assistance to overcome problems that interfere with their ability to provide counseling and advocacy services to others in ways that follow the ACA and CSJ Codes of Ethics.

C.6. Evaluation and remediation of counselors-in-training. CSJ professionals who are counselor educators clearly state to trainees prior to and throughout the training program that they are expected to:

(a) meet the expectations set forth in the Multicultural and Advocacy Competencies (Lewis, et al., 2002; Sue, Arredondo, \& McDavis, 1992) and

(b) provide ongoing evidence of their progress towards mastery of these competencies throughout the training program (ACA Code of Ethics, 2005, F.9.a.).

When aware that the inability of a trainee to achieve multicultural and advocacy competence can impede counseling performance, CSJ professionals who are counselor educators seek consultation to determine the need to dismiss or refer trainees for remedial assistance, assist them in securing remedial assistance when needed, assure them they have timely recourse to decisions, and provide them with due process according the institutional policies and procedures).

C.7. Roles and relationships between counselor educators and counselors-intraining. CS] professionals, who are counselor educators, are aware of the power differential in the relationship between faculty and trainees. They are aware of their potential to oppress 
and, consequently take steps to assure that their advisory and pedagogical practices are inclusive and that their expectations for trainees are not influenced by stereotypes or prejudices. When a conflict arises between a counselor educator and student advisee, CS] professionals ensure that the student's rights and privileges are not violated and that the student has an advocate and mentor to support his or her growth and development during the conflict resolution process (Ratts \& Hutchins, 2009).

\section{Code D: Research}

CSJ professionals have a responsibility to respond to the mission, vision and goals of CSJ by identifying topics for research that correspond to the principles supported by CSJ. CS] professionals recognize the importance of conducting research based on the established standards of the counseling profession (ACA Ethical Code, 2005) and particularly emphasize the rights of research participants, the importance of informed consent, protection of research participants' confidentiality and identity, and the provision of research information in a language that is understandable to the participant.

These professionals do so by taking into consideration the linguistic diversity present in the United States and the educational, social class, and cognitive ability level of research participants. Considering the imperatives of social justice counseling and advocacy, the research must be designed in collaboration with the constituents it will benefit (ACA, Ethical code, 2005; Ibrahim \& Cameron, 2004). The results of research must be accurately presented to, approved by, and used for the benefit of the persons in the communities that are involved in research endeavors.

D.1.a. Protection of research participants. When conducting research, especially with participants from historically oppressed and marginalized cultural groups, it is important to include representatives from the specific cultural group in the planning, approval, and execution of the research and analysis of the research results (Ibrahim \& Helms, 2008; Ibrahim \& Cameron, 2004). In conducting research, Glosoff and Kocet (2006), note that researchers must be aware of cultural meanings of confidentiality and privacy and how these issues may be viewed differently depending on the cultural worldview of the research participants (see ACA Code 2005, B.1.a).

The complexities in conducting research are further accentuated when dealing with sensitive information. Yick (2007) recommends that ethical questions about autonomy, informed consent, confidentiality, limits to confidentiality and protecting participants' safety and reducing distress need to be on the forefront when planning research projects among culturally diverse groups.

D.1.b. Designing, and executing a research study. When CSJ professionals conduct research they need to observe the guidelines of the appropriate Institutional Review Board (IRB). If they are not affiliated with an organization, and do not have access to IRB guidelines, they need to involve a professional in the research planning process who can help them address all the necessary safeguards required by an IRB (ACA 2005, G.1.).

To ensure historical social oppressions and beliefs are not perpetuated in research, CSJ professionals should conduct a mapping process when designing a study to understand the 
cultural worldview of a community or cultural group under study and avoid imposing mainstream assumptions (Ibrahim \& Cameron, 2004; Ibrahim \& Helms, 2008). Additionally, when analyzing research results, representatives of the community under study need to be involved in determining the meaning of such results. The focus of all research conducted among persons in diverse cultural communities must benefit these communities and not support of the research status quo (Ibrahim \& Helm; Ibrahim \& Cameron).

D.1.C. Publishing research results. CSJ professionals are encouraged to observe the guidelines of the ACA Code (2005) in ensuring integrity and competence in presenting research data that protects the confidentiality of the research participants and ensures that social justice and equity are critical factors that are addressed when presenting research results.

In addition, researchers are responsible for stating the implications of their studies for future research and to do so in ways that are intended to benefit the persons and communities who participate in their research endeavors. It is also important to adhere to those ethical guidelines that describe researchers' responsibilities as they relate to publishing the results of their research (ACA Ethical Code, 2005, G.5.b.).

\section{Code E: Professional Relationships and Consultation}

CSJ professionals recognize the importance of forming collaborative relationships with colleagues and accept the responsibility to promote the core values of CSJ in their interactions with colleagues in the profession and related disciplines. In addition, they recognize that it is their responsibility to be proactive in establishing collaborative alliances with representatives of oppressed client groups in order to partner in the planning and implementation of social justice advocacy interventions.

E.1. Relationships with colleagues. When interacting with colleagues, CSJ professionals work to strengthen interdisciplinary relationships by promoting a process that considers multiple perspectives regarding how to best serve clients (ACA Code of Ethics, 2005, D.1.c). If needed, they actively seek out alliances to pursue consultation and advocacy interventions at the institutional, community and societal levels to ameliorate the adverse impact of various social injustices among culturally-diverse clients and/or client groups. They accept the responsibility to promote interest in social justice and diversity issues among colleagues, produce and disseminate scholarship on the impact of oppression on human development, and provide mutual support for colleagues involved in social justice activities (Toporek, Lewis \& Crethar, 2009).

CSJ professionals recognize that when they encounter colleagues, who are practicing or teaching from an ethnocentric perspective that has the potential to create harm for clients/students, they have the responsibility to address the concern with the individual and to pursue other avenues if needed to try to assure client/student well being (ACA Code of Ethics, 2005, D.1.e.).

CSJ professionals are respectful of counseling approaches that differ from their own, especially indigenous helping practices, and seek to establish relationships with individuals providing such services in the communities where CSJ professionals work. 
CSJ professionals also work to identify social justice issues and educate other colleagues and professionals in schools, colleges, institutions, and local, national, and international communities as part of their advocacy efforts to eradicate social injustices.

E.2. Consultation. When providing consultation, CSJ professionals are careful to consider the worldview and sociopolitical experience of individual consultees or client groups. Particular care is taken in this area when CSJ professionals strive to understand the definition of specific problems, the goals for change, and the predicted consequences of counseling and advocacy interventions from the perspective of culturally different persons and communities that participate in such consultation endeavors. The hierarchical nature of the traditional consultation relationship is recognized and care is taken to encourage consultee growth in a manner consistent with the consultee's cultural frame of reference. This includes providing support for self-advocacy or engaging in advocacy on behalf of the client as collaboratively determined during the course of the consultation relationship.

E.3. Relationship with client and community groups. CSJ professionals strive to develop channels of communication and increase collaborative working relationships with representatives of oppressed client groups. They do so to:

(a) enhance the effectiveness of services provided to people in such groups and

(b) to form new alliances for social justice advocacy interventions. CSJ professionals also work to develop relations with colleagues from other disciplines not only to address social conditions that contribute to clients'/students' problems, but to also identify conditions requiring social justice advocacy through intra- and/or inter-professional collaboration.

E4. Employer policies. If CSJ professionals become aware of unjust/oppressive policies or procedures in the agency or institution where they are employed, they have the responsibility to collaborate with others in the organization to exercise systems advocacy interventions designed to effect changes in those policies/procedures. This could involve conducting research or analyzing data in order to enhance client group advocacy efforts by identifying issues and building a rationale for action. When such policies are potentially disruptive or damaging to clients or may limit the effectiveness of services provided and change cannot be affected, counselors take appropriate further action. Such action may include referral to appropriate certification, accreditation, state licensure organizations, complaints filed with appropriate civil rights and social justice organizations, or voluntary termination of employment (ACA Code of Ethics, 2005, D.1.h).

E.5 Responsibilities to the profession. CSJ professionals actively participate in local, state, and national associations that foster the development and improvement of social justice counseling and advocacy to promote the inclusion of the CSJ's core values in the policies and practices of those organizations.

\section{Part II :Background and Development Process of the CSJ Code of Ethics}

As the demographic transformation in the United States continues, persons from non-White cultural backgrounds have become more commonplace on counselor caseloads. Not only are mental health professionals being challenged to respect and adjust their professional practices 
to respond to cultural differences, they are increasingly being called upon to address social injustices experienced by clients and students in other marginalized and oppressed groups as well (Martin \& Midgely, 2006; National Center for Education Statistics, 2005).

Counseling as a profession has been criticized for implementing helping strategies that are primarily aimed at fostering individual intrapsychic interventions without recognizing and addressing contextual-environmental factors which contribute to the manifestation of mental health problems (House \& Martin, 1998; Ibrahim \& Arredondo, 1986; Ibrahim \& Ohnishi, 2001; Sue, Arredondo, \& McDavis, 1992; Toporek \& Liu, 2001; Toporek, Gerstein, Fouad, Roysircar, \& Israel, 2006; Toporek, Lewis, \& Crethar, 2009; Vera \& Speight, 2003). According to recent research, many people seeking counseling services suffer from trauma caused by racism, sexism, classism, homophobia, exclusion due to cultural and religious differences from the mainstream population of the United States, and unintentional and intentional acts of oppression (Carter \& Forsyth, 2009; House \& Martin, 1998; Ibrahim, 2008; Ibrahim \& Ohnishi, 2001; Prilleltensky, 1994; Prilleltensky \& Prilleltensky, 2003). These forms of injustice cause people immense pain and suffering resulting in shortened life span, ill health, anxiety, and depression (Carter \& Forsyth; Ibrahim; Prilleltensky, 1994; Prilleltensky \& Prilleltensky, 2003).

\section{Counselors for Social Justice}

Counselors for Social Justice (CSJ), one of the newer divisions of the American Counseling Association (ACA), was established 2003. The movement to create CSJ emanated from discussions focusing on the contexts in which mental health problems are created and maintained (Goodman, 2009). The group of counselors who founded CSJ did so to ensure that a professional organization existed to address social injustices and eradicate these social ills through innovative counseling and advocacy initiatives as well as through the implementation of new professional training and research endeavors. Although CSJ members include counselor educators, students, practitioners, and researchers they are unified in their value for the principles of democracy and respect for the rights of all persons to life, liberty, and the pursuit of happiness regardless of race, culture, ethnicity, gender, sexual orientation, age, social class, religion, disability, and citizen or immigrant status.

The mission of CSJ is to promote equity and end to oppression and injustice in communities, schools, workplaces, governments, and other social and institutional systems that negatively affect the psychological and physical health of clients, students, counselors and families (www.counselorsforsocialjustice.com). The organization hopes to create an equitable social order where all people can achieve their fullest potential, realize their capacity for mental health, and live a life of dignity and respect.

More specifically, the organization is committed to (a) challenging oppressive systems of power and privilege; (b) forming collaborative alliances with entities within and outside of the American Counseling Association to implement social justice advocacy strategies in counseling practice, counselor education programs, pre-K-20 schools, and community organizations; (c) disseminating research about sociopolitical and economic inequities facing counselors and clients/students in schools and communities; (d) maintaining an active support network online and in person for engaging in social justice activities in schools and communities; (e) providing professional development in counselor 
education programs, pre-K-16 schools, community agencies, and through ACA conference programs at national, regional and state levels to enhance counselor, counselor educator, and graduate student competency in social justice advocacy; and, (f) maintaining social justice advocacy resources online.

To provide more specific direction on how to accomplish these goals, Jane Goodman, then President of the American Counseling Association, established a task force on advocacy competence. This task force outlined a set of advocacy competencies that were formally endorsed by the American Counseling Association Governing Council in 2003 (Lewis, Arnold, House, \& Toporek, 2003). The competencies specify six domains of advocacy intervention: client/student empowerment, client/student advocacy, community collaboration, systems advocacy, public information, and social/political advocacy. The development and formal endorsement of these competencies represent a roadmap that requires counselors to acquire new knowledge and skills that are necessary to foster client/student self-advocacy as well as enabling counselors' to effectively advocate with and for clients/students in a broad range of institutional and community settings.

\section{Continuing Efforts to Institutionalize CSJ in the Counseling Profession}

Continuing efforts to institutional CSJ necessitated the development of a formal set of ethical standards that are designed to provide aspirational guidelines that social justice-oriented counselors are encouraged to follow in the work they do to foster clients' mental health and psychological by promoting the development of a more equitable social order (D'Andrea \& Heckman, 2008). It is further suggested that the progress that has been made in building the social justice counseling and advocacy movement necessitates the development of a set of professional ethical standards that delineated the work social justice counselors do in advocating for clients'/students' empowerment by removing systemic injustices and barriers in society.

Both the American Counseling Association (ACA) and the American Psychological Association (APA) have made advocacy an ethical responsibility (ACA, 2005; APA, 2002). Glosoff and Kocet (2006) note that integrated throughout the revised 2005 ACA Ethical Code (ACA, 2005) is an emphasis on multicultural/diversity issues facing counseling professionals. The introductory statements of most ACA Ethical Code sections speak to the ethical obligation counselors have to incorporate factors related to clients' cultural contexts in their professional practices. In this regard, Yick (2007) emphasizes that ethical issues related to professional counseling and advocacy practices need to be framed within clients' socio-cultural contexts that reflect understanding and respect for clients' group referenced value orientations and belief systems.

Further, when any group in society is marginalized, power dynamics complicate ethical principles of autonomy. As Pack-Brown, Thomas, and Seymour (2008) point out, this requires counselors to "thoughtfully reflect on how they might operate in an ethical manner to assist culturally diverse clients/students in adjusting to their environment [in order to] realize more satisfying and productive lives . . . and to support clients/students in changing those environmental conditions that perpetuate various forms of injustice and oppression that adversely affect clients'/students' mental health and sense of well being" (p. 297). 
To help counselors translate a social justice orientation from a theoretical and moral imperative to ethical practice, it is helpful to operationalize various aspects of the ACA Code of Ethics (2005) from a social justice perspective. Doing so will (a) provide counseling professionals with clear statements regarding the nature of their ethical responsibilities from a social justice perspective; (b) expand the mission of the counseling profession by articulating ethical standards from a social justice perspective; (c) delineate a set of social justice values that counselors are encouraged to adhere when they are involved in ethical decision-making; (d) establish principles that define ethical behavior and best practices for counselors who operate from a social justice perspective; (e) serve as guidelines to assist members in constructing a professional course of action that will best serve those utilizing counseling services; and, (f) serve as the basis for processing of ethical complaints and inquiries initiated against counselors who fail to implement professional services from a social justice counseling and advocacy perspective.

Toporek and Liu (2001) proposed ethical guidance for the work social justice-oriented counselors do. Much of the information Toporek and Liu present has relevance for developing an ethical code and set of standards for CSJ. This includes (a) information related the contexts in which clients live and work; (b) validation of oppressions faced by clients who are routinely subjected to various forms of racism, sexism, classism, homophobia, and other injustices such as those related to age, religion, disability, immigrant status; (c) recognition of the privileges that mental health professionals enjoy as a result of their education and training; (d) the expressed need to collaborate with clients to establish appropriate goals in counseling that includes possible strategies for fostering changes in the environments where clients live, study and work; (e) stating the importance of ensuring that any actions taken are primarily aimed at increasing the client's self efficacy and empowerment; (f) exploration of the knowledge, skills and commitment to take action to provide adequate protection when there is a hostile response toward clients when confronting acts of oppression within their own institutional and community settings; and, ( $\mathrm{g}$ ) issues related to consultation with community groups and other helping professionals to ensure ethical advocacy and social action to promote healthy human development. In addition, Toporek and Liu encourage counseling professionals to actively engage in the communities where they work to better understand the issues clients face in these communities.

To help counselors translate a social justice orientation from a theoretical and moral imperative to ethical practice, it is helpful to operationalize various aspects of the ACA Code of Ethics (2005) from a social justice perspective. Doing so will (a) provide counseling professionals with clear statements regarding the nature of their ethical responsibilities from a social justice perspective; (b) expand the mission of the counseling profession by articulating ethical standards from a social justice perspective; (c) delineate a set of social justice values that counselors are encouraged to adhere when they are involved in ethical decision-making; (d) establish principles that define ethical behavior and best practices for counselors who operate from a social justice perspective; (e) serve as guidelines to assist members in constructing a professional course of action that will best serve those utilizing counseling services; and, (f) serve as the basis for processing of ethical complaints and inquiries initiated against counselors who fail to implement professional services from a social justice counseling and advocacy perspective. It is with these intentions that CSJ embarked on the process to develop the Code of Ethics. 


\section{Code of Ethics Development Process and Timeline}

In March of 2009, Michael D'Andrea, then CSJ President, called for a task force to develop a set of professional ethics for social justice counseling. The development process that followed included consistent feedback and guidance from the CSJ Board and membership as the document developed. Details regarding the process and timeline are presented below.

3.11.2009 CSJ President Michael D'Andrea asks Farah Ibrahim to develop a CSJ Ethics Task Force that would develop a set of professional ethics for social justice counseling.

3.20.2009 Brainstorming session at ACA of CSJ-sponsored meeting to identify action plans to operationalize the CSJ Mission Statement, affirms idea that a CSJ Ethics Code is needed.

4.5.2009 Farah Ibrahim invites Julie Dinsmore and Diane Estrada to serve on a CSJ Ethics Task Force to create a draft of a CSJ Code of Ethics

4. 15.2009

Brainstorming on timeline and structure of the document. Reviewed:

- CSJ Mission Statement

- Advocacy Competencies

- Ethical codes of ACA and other ACA divisions

- Research in the literature-articles/books

6.1. $2009 \quad$ Research and writing assignments are determined

7.1. $2009 \quad$ Update to CSJ Board of progress of the Task Force

7.1. 2009- 1.1.2010 Writing and revising of the draft Code

2.1. 2010 Draft forwarded to President D'Andrea, shared with CSJ Board of Directors; draft Code sent out on CSJ listserv to solicit input

3.21. 2010 Town Hall Meeting Presentation at ACA Conference in Pittsburgh to 2010 take input from CSJ and ACA members on the draft Code

3.21.2010-9.1.2010 Input received is integrated into the document

9.11.2010 CSJ Code of Ethics endorsed by the CSJ Board

11.15.2010 Final edits made to CSJ Code of Ethics per input from the CSJ Board

\section{References}

American Counseling Association. (2005). ACA code of ethics. Retrieved from http://www.counseling.org/Resources/CodeOfEthics/TP/Home/CT2.aspx

American Psychological Association. (2002). Ethical principles of psychologists and ethical code. Washington, DC: Author 
Carter R. T., \& Forsyth J. M., (2009) A guide to the forensic assessment of race-based traumatic stress reactions. The Journal of the American Academy of Psychiatry and the Law, 37, 28-40.

D'Andrea, M., \& Heckman, E. F. (2008). A 40 year review of multicultural counseling outcome research: Outlining a future research agenda for the multicultural counseling movement. Journal of Counseling \& Development, 86(3), 356-363.

Eriksen, K., \& Kress, V. (2005). Beyond the DSM story: Ethical quandaries, challenges, and best practices. Thousand Oaks, CA: Sage.

Glosoff, H. L., \& Kocet, M. M. (2006). Highlights of the 2005 ACA code of ethics. In G. R. Walz, J. C. Bleuer, \& R. K. Yep (Eds.), Vistas: Compelling perspectives on counseling, 2006 (pp. 5-10). Alexandria, VA: American Counseling Association.

Goodman, J. (2009). Starfish, salmon, and whales: An introduction to the special issue. Journal of Counseling and Development, 87(3), 259.

House, R. M. \& Martin, P. J. (1998). Advocating for better futures for all students: A new vision for school counselors. Education, 119, 284-291.

Kocet, M. M. (2006). Ethical challenges in a complex world: Highlights of the ACA 2005 Ethical Code. The Journal of Counseling and Development, 84, 228-234.

Ibrahim, F. A., \& Arredondo, P. M. (1986). Ethical standards for cross-cultural counseling: Preparation, practice, assessment and research. Journal of Counseling and Development, 64, 349-351.

Ibrahim, F. A., \& Cameron, S. C. (2004). Racial-cultural ethics in research. In R. Carter (Ed.), Handbook of racial-cultural psychology and counseling (pp. 391-413). New York, NY: John Wiley and Co.

Ibrahim, F. A. \& Helms, B. J. (November, 2008). Paradigm shift for evaluation research: Incorporation of cultural dynamics in the evaluation process. Presentation at the Annual Association for Evaluation Research, Denver, CO.

Ibrahim, F. A., \& Ohnishi, H. (2001). PTSD and the minority experience. In D. Pope-Davis \& $\mathrm{H}$. Coleman (Eds.), Intersection of race, class, and gender in multicultural counseling (pp. 89-126). Thousand Oaks, CA: Sage.

Lewis, J. A., Arnold, M. S., House, R., \& Toporek, R. L. (2002). ACA Advocacy Competencies. from http://www.counseling.org/Publications/

Lonner, J., \& Ibrahim, F. A. (2008). Assessment in cross-cultural counseling. In P. B. Pedersen, J. Draguns, W. J. Lonner, \& J. Trimble (Eds.), Counseling across cultures, (6th ed., pp. 37-57). Thousand Oaks, CA: Sage. 
Martin, P., \& Midgley, E. (2006). Immigration: Shaping and reshaping America (2nd ed.). Population Bulletin, 61(4).

National Center for Education Statistics. (2005). The nation's report card. Washington, DC: Author.

Pack-Brown, S. P., Thomas, T. L., \& Seymour, J. M. (2008). Infusing professional ethics into counselor education programs: A multicultural/social justice perspective. Journal of Counseling \& Development, 86(3), 296-302.

Prilleltensky, I. (1994). The morals and politics of psychology: Psychological discourse and the status quo. Albany, NY: The State University of New York Press.

Prilleltensky, I., \& Prilleltensky, O. (2003). Towards a critical psychology practice. Journal of Health Psychology, 8, 172-210.

Ratts, M. J., \& Hutchins, M. (2009). ACA advocacy competencies: Social justice advocacy at the client/student level. Journal of Counseling and Development, 87, 269-275.

Roysircar, G. (2009). The big picture of social justice advocacy: Counselor heal society and thyself. Journal of Counseling and Development, 87, 288-294.

Sue, D. W., Arredondo, P., \& McDavis, R. (1992). Multicultural counseling competencies and standards: A call to the profession. Journal of Counseling \& Development, 70, 477-486.

Toporek, R. L., Lewis, J. A., \& Crethar, H. C. (2009). Promoting systemic change through the ACA Advocacy Competencies. Journal of Counseling \& Development, 87, 260-268.

Toporek, R. L., Gerstein, L. H., Fouad, N. A., Roysircar, G., \& Israel, T. (2006). Handbook for social justice in counseling psychology: Leadership, vision, and action. Thousand Oaks, CA: Sage.

Toporek, R.L., \& Liu, W.M. (2001). Advocacy in counseling psychology: Critical issues of race, class, and gender. In D.B. Pope-Davis \& H.L.K. Coleman (Eds.), The intersection of race, class and gender in counseling psychology (pp. 385-413). Thousand Oaks, CA: Sage Publications.

Vera, E, M, \& Speight, S, L, (2003), Multicultural competence, social justice, and counseling psychology: Expanding our roles. The Counseling Psychologist, 31, 253-272

Yick, A. (2007). Role of culture and context: Ethical issues in research with Asian Americans and immigrants in intimate violence. Journal of Family Violence, 22(5), 277-285. 